\title{
Quality of Individualized Education Program Goals of Preschoolers With Disabilities
}

\author{
Tânia Boavida, MPsy; Cecília Aguiar, PbD; \\ R. A. McWilliam, PbD; Júlia Serpa Pimentel, PbD
}

\begin{abstract}
Individualized education programs (IEPs) are a fundamental mechanism for making special education services unique for the child and for enhancing the developmental outcomes of children with disabilities. If written IEP goals diverge, however, from recommended practices, they might result in ineffective interventions. This study investigated the quality of Portuguese IEP goals written for 83 preschoolers with disabilities attending public preschool classrooms from 21 school groups from the District of Lisbon, Portugal. The quality of IEP goals was measured using the Goal Functionality Scale III (R. A. McWilliam, 2009) and the IEP/Individualized Family Service Plan Goals and Objectives Rating Instrument (A. R. Notari, 1988). Results showed that IEP goals were too broad, lacked functionality and measurability, and did not appropriately address skills within the context of natural routines and settings. Moreover, findings indicate that measurability was slightly higher the more severe the children's disabilities were and that autonomy (ie, self-help) goals were somewhat more functional and measurable than were social, language, cognitive, and motor goals. Findings raise concerns about the effectiveness of interventions based on such goals in enhancing children's developmental outcomes and suggest the need for clear guidelines on the development of effective IEPs and teacher training on developing high-quality goals. Key words: individualized education program goals, preschool, special education
\end{abstract}

$\mathbf{I}_{\mathrm{s}}^{\mathrm{N}}$ N PORTUGAL, where special education schools have been progressively converted into (and accredited as) resource centers for inclusion (Ministério da Educação, 2007), special education and early intervention legislation emphasizes inclusion (Decreto-Lei $\mathrm{n}$ $^{\circ}$ 3/2008; Decreto-Lei n. ${ }^{\circ}$ 281/2009). The last national reports indicated that approximately $2 \%$ of children enrolled in public preschools had disabilities (Inspecção-Geral da Educação, 2009) and $33 \%$ of preschool classrooms

Autbor Affiliations: ISPA, University Institute, Portugal (Ms Boavida and Drs Aguiar and Pimentel); and Siskin Children's Institute, Chattanooga, Tennessee (Dr McWilliam).

This work was funded by Fundação para a Ciência e a Tecnologia (SFRH/BD/44286/2008, SFRH/BPD/ 26383/2006).

Corresponding Autbor: Tânia Boavida, MPsy, Rua do Jardim do Tabaco, 34, 1149-041, Lisbon, Portugal (tboavida@ispa.pt). included at least 1 child with disabilities (Ministério da Educação, 2007).

Early childhood inclusion is a recommended practice because it embodies every child's right to full participation and, one hopes, to reaching his or her full potential (The Division for Early Childhood/National Association for the Education of Young Children [DEC/NAEYC], 2009). Positive results of inclusion are reported for both children with disabilities and children with typical development (Odom, 2000). Thus, the most appropriate intervention settings in early childhood are the contexts where sameage, typically developing children spend their time-that is, the family home and the child care or preschool classroom (Gamelas, 2003). Odom et al. (2004) cite several studies, suggesting that the inclusion of children with disabilities in preschool has benefits for children both with and without disabilities and their families and communities. They note, however, that many of the benefits occur 
only with intentional and planned intervention. Wolery (2000) maintains that the acquisition of important developmental skills in children with disabilities is possible only through effective mediation by the adult, the establishment of individualized goals, and the definition of strategies to achieve and monitor them. The DEC/NAEYC's first recommendation addresses the creation of high expectations for every child, considering that sharing of such expectations leads to the selection of appropriate goals.

The individualized education program (IEP) has been a fundamental mechanism for the individualization of teaching. The goals and objectives of the IEP, if developed through a systematic evaluation process and directly connected to intervention, can contribute to the individualization of services and improved development of children (Pretti-Frontczak \& Bricker, 2000). Quality goals and objectives are important for (a) professionals and natural caregivers to know what, how, when, and where to teach; (b) monitoring children's progress; and (c) evaluating and reporting the effects of the intervention. The IEP goals and objectives often diverge, however, from recommended practices, because they are poorly written and are not functional or contextualized (Grisham-Brown \& Hemmeter, 1998; Pretti-Frontczak \& Bricker, 2000; Yell \& Stecker, 2003), potentially resulting in ineffective interventions for children (Goodman \& Bond, 1993).

High-quality IEP goals and objectives must be family-centered and reflect recommended practices, which means that they should (a) be context-appropriate and supportive of natural caregivers' and families' routines, $(b)$ address skills necessary or useful to the child's participation in these routines, $(c)$ be measurable (ie, specific), (d) and have meaningful generalization and time frame criteria (Bailey et al., 1998; Jung \& McWilliam, 2005; McWilliam, 2010; McWilliam et al., 1998).

Although in Portugal the IEPs have been required by law since 1991 (Decreto-Lei ${ }^{\circ}$ $319 / 91$ ), we were not able to find any Portuguese data concerning the quality of the IEP goals and objectives. The recent Decree-Law number 281/2009, which established the national early childhood intervention system, included a very general requirement for an individual early intervention plan, with little guidance as to content. The other recent decree-law, number 3/2008 (Decreto-Lei $\mathrm{n}^{\circ} 3 / 2008$ ), upgraded the 1991 special education law and included changes related to the process for developing the IEPs and the structure of the IEPs-it required that the IEPs be jointly developed by the classroom teacher, the special education teacher, and parents. The law also defined the International Classification of Functioning, Disability and HealthChildren and Youth (World Health Organization, 2007) as the method for documenting children's functioning and the environmental facilitators and barriers to social and educational participation. Despite these requirements, no official guidelines on the formulation of the IEP goals and objectives are provided, and professional training on writing high-quality outcomes for children is virtually nonexistent.

In this study, we aimed to (a) document the quality of the goals (or objectives when goals were merely indications of the developmental domain being addressed) in IEPs of Portuguese children with disabilities attending inclusive public preschool settings; $(b)$ investigate the associations among children's severity of disability and the quality of the IEP goals; and (c) investigate the quality of the IEP goals as a function of developmental domain. On the basis of the literature mentioned earlier, we expected goals to be of lower quality when the child's disability was more severe.

\section{METHODS}

\section{Participants}

Data were collected from 21 randomly selected school groups from the existing 145 school groups in the District of Lisbon (a district with around 2200000 inhabitants). In Portugal, a school group is a conglomerate of schools across ages, with some groups having resources for specific needs. From the Web 
site of the Direcção Regional de Educação de Lisboa (Lisbon Regional Education Directorate), a list of the 145 school groups of the District of Lisbon was made. After assigning numbers to all groups, a random-number sequence (developed from an Internet program) was applied. Letters of invitation describing the research and soliciting information about inclusive preschool classrooms (ie, classrooms with at least 1 child with disabilities) in the school group were sent to the board of directors of the first 50 groups randomly selected. The sample-size goal was 100 children, determined through power analysis. Because of a low positive response rate (32\%) from the first 50 groups, letters to the next 50 groups were sent. Once school groups expressed interest in the study, meetings with all the classroom teachers and the special education teachers from the interested school groups were held. In these meetings, written information describing the research and consent forms were distributed to all potential participants, including families of children with disabilities. The result of this recruitment procedure was 32 special education teachers from 21 school groups. (Classroom teacher participation was not relevant for this analysis.)

Eighty-three preschoolers with disabilities participated, meaning that their IEPs written by 32 special education teachers were collected. Therefore, the IEPs were nested within teachers at a range of 1 to 8 per teacher. Teachers' age averaged 43.83 years $(\mathrm{SD}=$ 9.29), their education averaged 17.41 years $(\mathrm{SD}=1.27)$, and their experience in special education averaged 9.39 years $(S D=6.42)$. Children's age averaged 67.24 months (SD = 13.36), and $37 \%$ of them presented global development delay, $25.9 \%$ were diagnosed with an autism spectrum disorder, $8.6 \%$ had cerebral palsy, $8.6 \%$ had multiple disabilities, and the remaining $19.7 \%$ had other types of disabilities.

\section{Measures and procedures}

Special education teachers were instructed to complete a questionnaire about themselves and the children with disabilities, including a measure of children's (dis)abilities, and submit it with the children's IEPs.

\section{ABILITIES Index}

The profiles of the children's abilities and limitations were based on the ABILITIES Index (Simeonsson \& Bailey, 1991). ABILITIES is an acronym for a tool covering 9 dimensions shown in Table 1. It was designed to include the following characteristics: (a) a relatively stable and comprehensive profile of a child's abilities in 9 areas; $(b)$ for each dimension or area, a definition of functioning by 6 ordinal levels of difficulty $(1=$ normal, $2=$ suspected difficulty, $3=$ mild difficulty, $4=$ moder ate difficulty, $5=$ severe difficulty, and $6=$ profound difficulty); (c) ordinal levels characterized in functional terms and not in technical terms to facilitate the classification by caregivers, including parents and professionals; (d) classification able to be made on the basis of observation, prior knowledge of the child, or other specific information; (e) classifications reflecting more relative than absolute standards for ability or disability levels; (f) classifications to establish a holistic profile of intraindividual differences; $(g)$ a profile emphasizing the abilities and disabilities relevant to individualized intervention; and $(b)$ a profile rather than simply a label, thereby minimizing simplistic categorization of children (Simeonsson, Bailey, Smith, \& Buysse, 1995). For research purposes (and not as a way to generate a composite score for clinical use), one can calculate an overall severity score by multiplying the assigned rating in each of the 9 dimensions by the following experimental weights proposed by R. J. Simeonsson (written communication, September 9, 2006): Audition $=1.8$; Social Skills $=1.4$; Inadequate Behavior $=1.7$; Intellectual Function = 2.0; Limbs, Hands $=1.5$; Limbs, Arms = 1.4; Limbs, Legs $=1.6$; Understanding $=1.2$; Communicating with others $=1.0$; Tonicity, Tightness $=1.5$; Tonicity, Looseness $=1.4$; Overall Health $=1.5$; Vision $=1.7$; and Structural Status $=1.3$. In this study, the Cronbach $\alpha$ coefficient for all 19 items was .87. 
Table 1. ABILITIES Index Dimensions (Simeonsson \& Bailey, 1991)

\section{Dimension}

Audition (Hearing)

Behavior social skills

Intellectual function (thinking and reasoning)

Limbs (use of hands, arms, and legs)

Intentional communication (understanding and communicating with others)

Tonicity (muscle tone)

Integrity of physical health (overall health)

Eyes (vision)

Structural status (shape, body form, and structure)

\section{Definition}

Child's ability to hear in everyday activities. Score hearing for each ear separately. Score of 6 (profound loss) means that the child has no hearing. Rate the child's hearing without a hearing aid. If the child uses a hearing aid, indicate this on the back of the form.

Two ratings are made in this area, one for social skills and one for inappropriate or unusual behavior. Social skills refer to the child's ability to relate to others in a meaningful manner. Inappropriate and unusual behavior may include fighting, hitting, screaming, rocking, hand flapping, biting self, etc.

This rating reflects the child's abilities to think and reason. Think about the way the child solves problems and plays with toys and compare this to other children of the same age.

Think about the child's ability to use his or her hands, arms, and legs in daily activities. Score left and right limbs separately. A score of 6 (profound difficulty) means that the child has no use of a limb.

Two ratings are made, one for the child's ability to understand others and one for the child's ability to communicate with others. This rating includes attempts to communicate in ways other than talking (signs, gestures, and picture boards). Think about the child's ability to understand and communicate with others and compare this to other children of the same age.

Think about the child's muscle tone. Normal means that the child's muscles are neither tight nor loose. If the child's muscle tone is not in the normal range, place an " $\mathrm{X}$ " in each box that indicates the degree of tightness or looseness or both. Two ratings should be made since, in some children, tightness or looseness can vary in different parts of the body or from one time to the next.

Think about the child's general health. Normal means the usual health problems and illnesses typical for a child this age. If there is a health problem, ratings should be made indicating the degree to which health problems limit activities. Ongoing health problems may include seizures, diabetes, muscular dystrophy, cancer, etc.

Think about the child's ability to see in everyday activities. Score both left and right eye. A score of 6 (profound loss) means that the child has no vision. Rate the child's vision without glasses. If the child uses glasses, indicate this on the back of the form.

This rating reflects the form and structure of the child's body. Normal means that there are no differences associated with form, shape, or structure of the body parts. Differences in form include conditions like cleft palate or club foot; differences in structure include conditions like curved spine and arm or leg deformity. Ratings should indicate how much these differences interfere with how the child moves, plays, or looks. 
To evaluate the quality of the IEP goals written by the special education teachers, 2 instruments were used: the Goal Functionality Scale III (GFS III; McWilliam, 2009) and the IEP/Individualized Family Service Plan (IFSP) Goals and Objectives Rating Instrument (GORI; Notari, 1988). A total of 3158 goals from 83 IEPs were coded individually, first with the GFS III and second with GORI. Within every IEP, all goals were first coded using item number 1 , and then all goals were coded using item number 2 , and so forth. The use of 2 instruments was to determine convergent validity of the scores and to capture quality features that each instrument idiosyncratically included.

\section{GFS III}

The GFS III was designed to evaluate the quality of IFSP/IEP goals/outcomes. It consisted of 7 items: (a) indication of participation in routines (engagement), (b) specificity of the desired behavior, (c) necessity of the skill, (d) quantification of the acquisition criterion, $(e)$ relevance of the acquisition criterion, $(f)$ relevance of the generalization criterion, and $(g)$ relevance of the timeframe criterion. Each goal/outcome was rated independently on a scale of 1 to 4: not at all, somewhat, much, or very much.

The GFS III ratings of IEP goals were made by 2 researchers who were trained to a criterion of $98 \%$ of exact agreement and an intraclass correlation coefficient (ICC) of .58 . One of the researchers rated all of the IEPs and the other one rated $20 \%$ of them. The obtained agreement was $99.24 \%$ for the item "participation in routines," with a weighted $\kappa$ $\left(\kappa_{\mathrm{w}}\right)$ of .62 and an ICC of .75; $95.72 \%$ for the item "measurability," with a $\kappa_{\mathrm{w}}$ of .59 and an ICC of .61; and $92.18 \%$ for the item "necessity or usefulness," with a $\kappa_{\mathrm{w}}$ of .54 , and an ICC of .56 .

Items 5, 6, and 7 on the GFS III are about the quality of criteria for accomplishing the goal. Although these items were rated, no variance was found (ie, all goals were rated with a score of 1 and so they were excluded from further analyses). Item 4 , also related to cri- teria, was also excluded because although exact agreement was $99.62 \%, \kappa_{\mathrm{w}}$ and ICC were not acceptable (.13 and .45 , respectively). Therefore, only 3 GFS III items remained for analysis.

\section{IEP/IFSP GORI}

The GORI was designed to evaluate IFSP/IEP goals and objectives in 5 dimensions: (1) functionality, (2) generality, (3) instructional context, (4) measurability, and (5) hierarchical relationships among objectives (ie, how closely the objective is related to the goal). Each goal was rated independently to determine the presence or absence of 10 different quality indicators. A score of 0 or 1 was assigned to the absence or presence (respectively) of the indicator. To examine the hierarchical relationship between an objective and its corresponding goal, an additional indicator was used with scores of 0,1 , or 2 , if the objective was completely unrelated to the goal, if it simply restated the goal, or if it was a necessary step toward attainment of the goal, respectively. For further description of indicators included in each quality dimension, see Table 2. The overall quality of a specific goal was the sum of the scores across the quality indicators, so the higher the score for a goal the higher the quality (Pretti-Frontczak \& Bricker, 2000). In this study, because the Cronbach $\alpha$ coefficient for all 11 indicators was .92 , a single composite measure-the GORI overall mean score-computed as the mean of scores across all goals was used. For each goal, we computed the sum of scores and, for each IEP, we computed the mean of scores across all goals. The possible range for this composite score was 0 to 12 .

The GORI was rated by only 1 researcher, who conducted intrarater agreement checks in $15 \%$ of all IEPs 1 week later. In this study, mean exact intrarater agreement was $97 \%$ and mean $\kappa$ was .79. Previously, Pretti-Frontczak and Bricker (2000) reported an interrater percentage agreement of greater than $80 \%$ and a mean $\kappa$ of .72 . 
Table 2. Percentage of Goals per Individualized Education Program Rated Positively on Each Goals and Objectives Rating Instrument Quality Indicator

\begin{tabular}{|llrr|}
\hline \multirow{2}{*}{ Dimension } & \multicolumn{1}{c}{ Indicator } & $\boldsymbol{M}, \boldsymbol{\%}$ & \multicolumn{1}{c|}{ SD } \\
\hline Functionality & Skill needed to participate in most or all daily activities & 25.52 & 15.35 \\
& Skill needed to complete most or all daily activities & 8.30 & 7.79 \\
Generality & Skill represents a general concept or class of responses & 10.57 & 8.98 \\
& Skill can be adapted to a variety of disabilities & 46.72 & 25.70 \\
& Skill can be generalized across a variety of settings, & 27.88 & 16.77 \\
Context & materials, and/or people & 30.50 & 17.64 \\
& Skill can be taught across daily activities & 24.33 & 15.02 \\
Measurability & Skill can be taught by various team members during & & \\
& $\quad$ everyday situations & 33.57 & 20.58 \\
& Skill can be seen or heard & 10.58 & 10.49 \\
Hierarchical relations & 2.00 & 3.52 \\
& Skill can be counted or measured & 0.12 & 0.61 \\
& Inclusion of performance criterion & 0.00 & 0.00 \\
& The objective restated the goal & & \\
& The objective was a necessary step toward attainment of & & \\
& the goal & &
\end{tabular}

\section{Data analysis}

Descriptive data on ABILITIES, GFS III, and GORI were examined to determine the level of functioning of participating children, the number of goals in each IEP, and the quality of IEP goals. Analysis of variance (Kruskal-Wallis test) and post hoc assessment of independent samples (Mann-Whitney $U$ test) were run to determine whether the quality of IEP goals varied by developmental domain. Nonparametric statistics were chosen because of violations of the normality assumption on scores of the quality of IEP goals. The first author assigned each goal to 1 of the following 5 domains: motor, autonomy (ie, self-help), language, social, and cognition. Finally, to determine the convergent validity of the scores of GFS III and GORI and the associations between IEP quality indicators and children's degree of disability, Spearman $\rho$ correlation coefficients were computed.

\section{RESULTS}

Fifteen percent of participating children were rated by special education teachers as having a profound disability in at least 1 domain on the ABILITIES Index. Using the same criterion of one domain, $46 \%$ were rated as having a severe disability, $27 \%$ were rated as having a moderate disability, $10 \%$ were rated as having a mild disability, and $2 \%$ were rated as having a suspected disability.

The number of goals per IEP varied widely, ranging from 4 to $95(M=38.18, \mathrm{SD}=20.75)$. The frequency of each GORI indicator (per IEP) ranged from $0 \%$ to $46.72 \%$, with hierarchical relations among objectives and inclusion of performance criteria virtually nonexistent and generality related to likelihood of adaptation to various disabilities characterizing almost half the goals (Table 2).

Table 3 presents the mean scores obtained on the GFS III items and on the GORI composite measure. It also includes descriptive statistics of IEP goal quality indicators by 5 developmental domains. Computation of a Kruskal-Wallis test with developmental domains as independent variables and GFS III indicators and GORI mean quality as dependent measures indicated that all 4 measures of IEP goal quality varied as a function of developmental domain: for participation in routines, 
Table 3. Mean Quality of Goals by Developmental Domain

\begin{tabular}{|c|c|c|c|c|c|}
\hline & No. of goals & $\boldsymbol{M}$ & SD & Min & $\operatorname{Max}$ \\
\hline \multicolumn{6}{|l|}{ Goal Functionality Scale III } \\
\hline Participation in routines & 3158 & 1.10 & 0.10 & 1.00 & 1.39 \\
\hline Motor development & 821 & 1.00 & 0.09 & 1.00 & 3.00 \\
\hline Autonomy & 454 & 1.53 & 0.59 & 1.00 & 4.00 \\
\hline Language & 303 & 1.01 & 0.11 & 1.00 & 2.00 \\
\hline Social development & 433 & 1.16 & 0.47 & 1.00 & 4.00 \\
\hline Cognition & 1147 & 1.01 & 0.09 & 1.00 & 2.00 \\
\hline Measurability & 3158 & 1.48 & 0.25 & 1.00 & 2.05 \\
\hline Motor development & 821 & 1.68 & 0.59 & 1.00 & 3.00 \\
\hline Autonomy & 454 & 1.68 & 0.59 & 1.00 & 3.00 \\
\hline Language & 303 & 1.47 & 0.59 & 1.00 & 3.00 \\
\hline Social development & 433 & 1.28 & 0.48 & 1.00 & 3.00 \\
\hline Cognition & 1147 & 1.49 & 0.59 & 1.00 & 3.00 \\
\hline Necessity or usefulness & 3158 & 1.58 & 0.27 & 1.00 & 2.00 \\
\hline Motor development & 821 & 1.27 & 0.56 & 1.00 & 4.00 \\
\hline Autonomy & 454 & 2.38 & 0.93 & 1.00 & 4.00 \\
\hline Language & 303 & 1.50 & 0.59 & 1.00 & 4.00 \\
\hline Social development & 433 & 1.73 & 0.81 & 1.00 & 4.00 \\
\hline Cognition & 1147 & 1.55 & 0.64 & 1.00 & 4.00 \\
\hline $\begin{array}{l}\text { Goals and Objectives Rating } \\
\text { Instrument-Mean quality }\end{array}$ & 3158 & 2.20 & 1.22 & 0.00 & 4.16 \\
\hline Motor development & 821 & 1.89 & 2.15 & 0.00 & 9.00 \\
\hline Autonomy & 454 & 4.26 & 3.16 & 0.00 & 9.00 \\
\hline Language & 303 & 2.46 & 2.90 & 0.00 & 9.00 \\
\hline Social development & 433 & 1.83 & 2.64 & 0.00 & 8.00 \\
\hline Cognition & 1147 & 2.38 & 2.59 & 0.00 & 9.00 \\
\hline
\end{tabular}

Abbreviations: max, maximum; min, minimum.

$H(4)=1037.28, P<.001$; for measurability, $H(4)=178.33, P<.001$; for necessity or usefulness, $H(4)=546.36, P<.001$; and for the GORI mean quality score, $H(4)=191.51, P<$ .001 .

Post hoc comparisons and Cohen $d$ on IEP goals quality indicators by developmental domains are shown in Table 4. Examination of effect sizes shows some large differences, such as between motor development and autonomy on participation and necessity; between motor development and social development on measurability; between autonomy and language on participation and necessity; between autonomy and social development on measurability; and between autonomy and cognitive development on participation and necessity. No differences were found between language and cognition, and only small differences were found between motor development and language. Post hoc comparisons, using Mann-Whitney $U$ tests, indicated all but 9 differences between mean scores of IEP goal quality, by developmental domain, were statistically significant.

Finally, Table 5 lists the Spearman correlation coefficients among the quality of IEP goals and children's degree of disability. The GFS III items and the GORI overall score were generally correlated. We found a statistically significant but nonnoteworthy association between the GORI overall score and participation in routines and strong associations between the GORI and measurability 


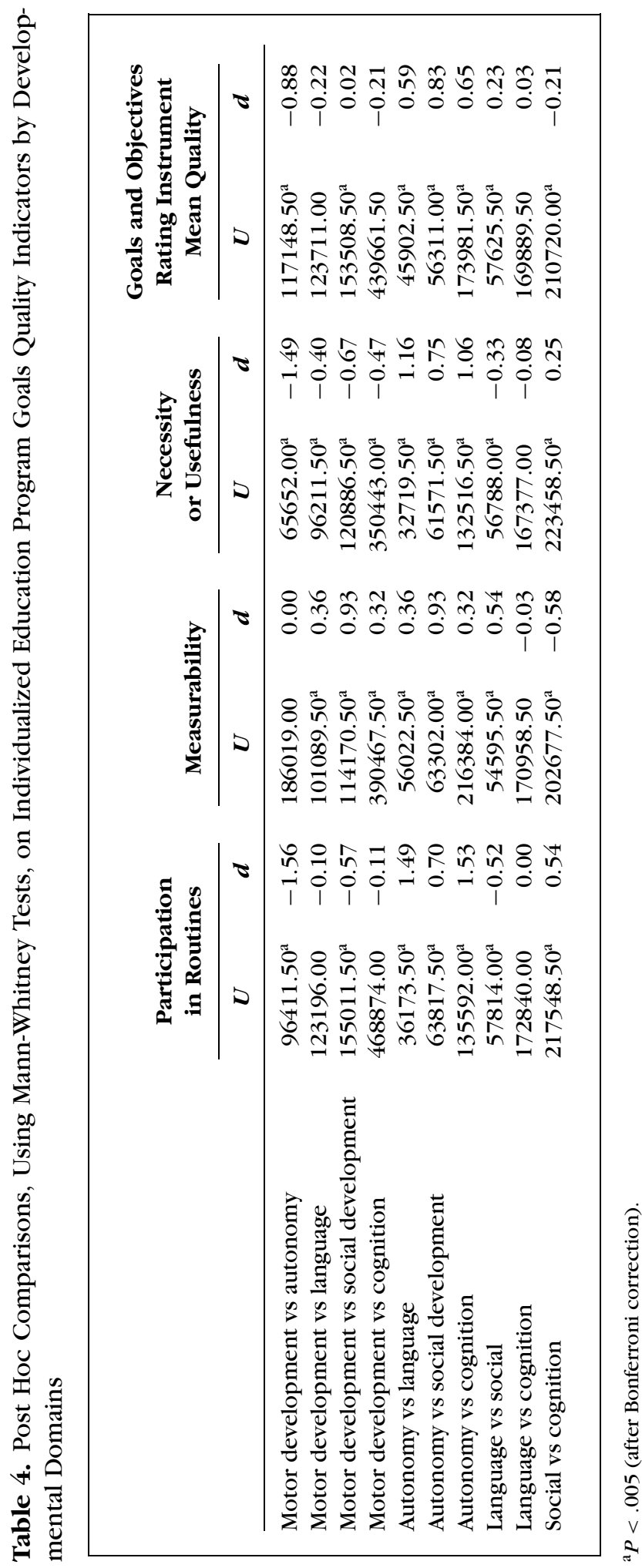


Table 5. Spearman's $\rho$ correlation among Individualized Education Program goal quality variables

\begin{tabular}{|lcccc|}
\hline & 1 & 2 & 3 & 4 \\
\hline Participation in routines $(\mathrm{N}=83)$ & $\ldots$ & & & \\
Measurability $(\mathrm{N}=83)$ & $.26^{\mathrm{a}}$ & $\ldots$ & & \\
Necessity or usefulness $(\mathrm{N}=83)$ & $.39^{\mathrm{b}}$ & $.52^{\mathrm{b}}$ & $\ldots$ & \\
Goals and Objectives Rating Instrument-mean quality $(\mathrm{N}=83)$ & $.25^{\mathrm{a}}$ & $.76^{\mathrm{b}}$ & $.63^{\mathrm{b}}$ & $\ldots$ \\
Severity of disability $(\mathrm{N}=57)$ & .21 & $.26^{\mathrm{a}}$ & .11 & $.23^{\mathrm{a}}$ \\
& & & & \\
\hline
\end{tabular}

${ }^{\mathrm{a}} P<.05$.

${ }^{\mathrm{b}} P<.01$.

and necessity or usefulness. We also found statistically significant associations among the 3 indicators of the GFS III: a nonnoteworthy association between participation in routines and measurability, a small association between participation in routines and necessity and usefulness, and a moderate association between measurability and necessity or usefulness. The severity of disability presented a statistically significant but nonnoteworthy association with measurability and GORI. The main conclusion from these data is that variables of the IEP quality are associated and yet measure different specific characteristics.

\section{DISCUSSION}

By focusing on the quality of the IEP goals for children with disabilities attending inclusive preschool classrooms in the District of Lisbon (an area where about one-fifth of the Portuguese people live), the current study adds previously unavailable information on Portuguese early childhood special education services. According to our findings, the IEPs written under the 1991 special education law included low-quality goals that might not result in individualized and effective interventions for children. These findings also have implications for other countries because the variables measured are not necessarily ethnocentric to Portugal.

As in prior research (Lynch \& Beare, 1990), the most frequently observed indicators of the quality of goals were related to generalization. In our study, half the goals addressed skills that could be functional for children across various ability levels, including children without disabilities, and around one-fourth were related to skills that could be generalized across a variety of settings, materials, or people. This relatively higher frequency of generalizable goals may be related to fundamentally vague and general outcomes, which Lynch and Beare found and Yell and Stecker (2003) described. For example, a goal stating a child will walk is generalizable but nonspecific (the extent, conditions, and levels of assistance are unspecified). Therefore, although generalizability of goals is generally desired, that is not true at the expense of specificity.

We also found a high number of goals per IEP, which often can lead to teachers' failing to monitor practices because they have too many requirements (Fuchs \& Shinn, 1989). According to Shinn and Shinn (2000), numerous goals are written for each deficit area because educators are unclear about what behaviors are important to measure, so they focus on satisfying a procedural requirement rather than improving student achievement. The rather low scores on the measurability of outcomes are consistent with Shinn and Shinn's argument, with only one-third of goals addressing skills that can be seen or heard, a 10th of goals addressing skills that can be counted or measured, and no more than onefiftieth of goals having performance criteria. The low mean on the GFS III measurability 
item and the exclusion of items based on no variance (all goals rated 1) provide further support for the notion that the high number of goals and the generalization findings may be associated with vague and general outcome statements. This absence of criteria for successful performance is consistent with prior findings (Fuchs \& Shinn, 1989; Lynch \& Beare, 1990; Yell \& Drasgow, 2000). Results also suggest that Portuguese preschoolers' IEP goals do not appropriately focus on skills needed for participation in naturally occurring daily routines.

Low functionality and measurability as well as insufficient focus on natural routines and environments are consistent with previous investigations of IEP goals (Goodman \& Bond, 1993; Grisham-Brown \& Hemmeter, 1998; Pretti-Frontczak \& Bricker, 2000; Yell \& Stecker, 2003), although results reported here indicate greater cause for concern. Findings also suggest that the measurability of goals is positively associated with the child's severity of disability. Because children with more severe disabilities might make progress in smaller steps than higher functioning children, it might be necessary for special education teachers to pay more attention to the measurability criterion. Therefore, this association may be due to special education teachers' increased efforts to write operationalized IEP goals for children with greater needs or to a predominance of autonomy goals for children with more severe disabilities. The quality of the IEP goals varied as a function of developmental domain, with goals that address autonomy skills consistently rated higher on participation in routines, measurability, necessity or usefulness, and overallr mean quality (GORI). These results suggest that teachers may have less difficulty understanding the necessity and functionality of independence (ie, self-help) skills and translating them into ap- propriate outcomes. These results were expected as autonomy skills, that is, behaviors that are needed for important daily routines such as dressing, bathing, eating, and so on, almost naturally translate into necessary, useful, and functional outcomes.

Limitations of this study include nesting of the IEPs within teachers, which may have contributed to decreased data variability and representativeness. Also, such nesting was not considered in data analysis because we considered the existence of data independence at the child level. Furthermore, data presented here are based exclusively on researchers' ratings of IEP goals. Inclusion of parents' and other natural caregivers' ratings of IEP goals would have provided relevant information on the social validity of such goals. The rating scales used here to assess the quality of the IEP goals focus on the characteristics of goals as final products and do not capture directly the features of their process of elaboration (such as participation of parents in writing the goals). Finally, cultural issues should also be considered because measures used in this study were developed in the United States. Although quality indicators included in GFS III and GORI are consistent with the current early childhood special education theoretical framework in Europe as well as the United States, there is no available information on their cultural appropriateness (ie, we do not know to what extent Portuguese teachers or families value such indicators). Despite these limitations, the data are robust enough to provide important information for the field, to add to the body of literature on the IEP quality, and to contribute to an understanding of functionality in early intervention. These findings suggest that clear guidelines on the development of IEP goals and teacher training on how to write meaningful, measurable, and functional goals are warranted.

\section{REFERENCES}

Bailey, D. B., Jr., McWilliam, R. A., Darkes, L. A., Hebbler, K., Simeonsson, R. J., Spiker, D., et al (1998). Family outcomes in early intervention: A framework for pro- gram evaluation and efficacy research. Exceptional Children, 64, 313-328.

Division of Early Childhood/National Association for the 
Education of Young Children. (2009). Early childhood inclusion: A joint position statement of the Division for Early Childbood (DEC) and the National Association for the Education of Young Children (NAEYC). Chapel Hill, NC: The University of North Carolina, FPG Child Development Institute.

Decreto-Lei n. ${ }^{\circ}$ 3/2008 (Decree-Law 3/2008). Ministério da Educação. Diário da República - $1^{\mathrm{TM}}$ Série n. ${ }^{\circ} 4$ 7 de Janeiro de 2008, pp. 154-164.

Decreto-Lei n. ${ }^{\circ}$ 281/2009 (Decree-Law 281/2009). Diário da República - $1^{\mathrm{TM}}$ Série n. ${ }^{\circ} 193$ - 6 de Outubro de 2009, pp. 7298-7301. Decreto-Lei n. 319/91 (Decree-Law 319/91). Diário da República - I Série-A, n. ${ }^{\circ} 193$ - 23 de Agosto de 1991, pp. 4389-4393.

Fuchs, L. S., \& Shinn, M. R. (1989). Writing CBM IEP objectives. In M. R. Shinn (Ed.), Curriculum-based measurements: Assessing special children (pp. 130152). New York: Guilford Press.

Gamelas, A. M. (2003). Contributos para o Estudo da Ecologia de Contextos Pré-Escolares Inclusivos [Contributions to the study of inclusive preschool contexts ecology]. Lisboa: Ministério da EducaçãoDepartamento da Educação Básica.

Goodman, J., \& Bond, L. (1993). The individualized education program: A retrospective critique. Journal of Special Education, 26, 408-422.

Grisham-Brown, J. F., \& Hemmeter, M. L. (1998). Writing IEP goals and objectives: Reflecting an activity-based approach to instruction for young children with disabilities. Young Exceptional Children, 1(3), 2-10.

Inspecção-Geral da Educação [General Inspectorate of Education] (2009). Organização do Ano Lectivo de 2008/2009-Relatório Nacional. Versão de trabalbo. [Organization of the Academic Year 20082009-National Report. Working version]. Lisbon: Author.

Jung, L. A., \& McWilliam, R. A. (2005). Reliability and validity of scores on the IFSP Rating Scale. Journal of Early Intervention, 27, 125-136.

Lynch, E. C., \& Beare, P. L. (1990). The quality of IEP objectives and their relevance to instruction for students with mental retardation and behavioral disorders. Remedial and Special Education, 11, 48-55.

McWilliam, R. A. (2009). Goal Functionality Scale III. Chattanooga, TN: TEIDS-Plus Study, Siskin Children's Institute.

McWilliam, R. A. (2010). Routines-based early intervention: Strategies for supporting young children with disabilities. Baltimore, MD: Brookes Publishing.

McWilliam, R. A., Ferguson, A., Harbin, G. L., Porter, P., Munn, D., \& Vandiviere, P. (1998). The familycenteredness of individualized family service plans. Topics in Early Childbood Special Education, 18, 69-82.
Ministério da Educação [Ministry of Education] (Ed.). (2007). Relatório Nacional sobre a Organização do Ano Lectivo de 2006/2007 [National Report on the Organization of the Academic Year 2006/2007]. Lisbon: Inspecção-Geral da Educação.

Notari, A. R. (1988). The utility of a criterion-reference instrument in the development of the individualized education plan goals for infants and young children. Unpublished doctoral dissertation, University of Oregon, Eugene, Oregon.

Odom, S. (2000). Preschool inclusion: What we know and were we go from here. Topics in Early Childbood Education, 20, 20-27.

Odom, S. L., Vitztum, J., Wolery, R., Lieber, J., Sandall, S., Hanson, M. J., et al (2004). Preschool inclusion in the United States: a review of research from an ecological systems perspective. Journal of Research in Special Educational Needs, 4, 17-49.

Pretti-Frontczak, K., \& Bricker, D. (2000). Enhancing the quality of Individualized Education Plan (IEP) goals and objectives. Journal of Early Intervention, 23, 92-105.

Shinn, M. R., \& Shinn, M. M. (2000). Writing and evaluating IEP goals and making appropriate revisions to ensure progress and participation in general curriculum. In C. Telzrow \& M. Tankelersley (Eds.), IDEA Amendments of 1997: Practice guidelines for school-based teams (pp. 351-382). Bethesda, MD: National Association of School Psychologists.

Simeonsson, R. J., \& Bailey, D. B. (1991). ABILITIES Index. Chapel Hill, NC: Frank Porter Graham Development Center, University of North Carolina.

Simeonsson, R. J., Bailey, D. B., Smith, T., \& Buysse, V. (1995). The ABILITIES of children: A functional approach to classification. Chapel Hill, NC: Frank Porter Graham Development Center, University of North Carolina.

Wolery, M. (2000). Recommended practices in childfocused interventions. In S. Sandall, M. E. McLean, \& B. J. Smith (Eds.), DEC recommended practices in early intervention /early childbood special education (pp. 29-37). Longmont, CO: Sopris West.

World Health Organization. (2007). International Classification of Functioning, Disability and HealthChildren and Youth. Geneva, Author.

Yell, M. L., \& Drasgow, E. (2000). Litigating a free appropriate public education: The Lovaas hearings and cases. The Journal of Special Education, 33, 205214.

Yell, M.L., \& Stecker, P. M. (2003). Developing legally correct and educational meaningful IEPs using curriculum-based measurement. Assessment for Effective Intervention, 28, 73-88. 